\title{
Advances in Clinical Toxicology
}

\section{Acute Kidney Injury in Children Following Multiple Wasp Stings and its Immediate Outcome}

\author{
Tahura $\mathrm{S}^{1 *}$ and Hanif $\mathbf{M}^{2}$ \\ ${ }^{1}$ Assistant Professor of Pediatrics. Bangladesh Institute of Child Health (BICH), Dhaka \\ Shishu (Children) Hospital, Bangladesh
}

${ }^{2}$ Professor and Head. Department of Pediatric Nephrology and Renal diseases, Bangladesh Institute of Child Health (BICH), Dhaka Shishu (Children) Hospital, Bangladesh

*Corresponding author: Sarabon Tahura, Assistant Professor of Pediatrics, Bangladesh Institute of Child Health (BICH), Dhaka Shishu (Children) Hospital, Dhaka-1207, Bangladesh, Tel: +8801716248281; E-mail: drsarabon@yahoo.com

\section{Abstract}

Background: Wasp bites usually bring temporary discomfort and pain, but on occasion, massive wasp stings can cause fatal allergic reactions and multiple organ failure including acute kidney injury (AKI), hepatic failure and circulatory collapse.

Objective: This study was undertaken to find out the type of renal injury and immediate outcome of treatment of AKI following multiple wasp stings among children.

Methods: It was a prospective study conducted in Dhaka Shishu (Children) Hospital from July 2012 to June 2014 . During this period admitted children with AKI following wasp bite were included in the study. Detail history was recorded and clinical examinations and investigations including renal biopsy were performed to every patient. All patients underwent peritoneal dialysis.

Result: Total 18 children were admitted with AKI following multiple wasp stings during the study period. Among them male were $14(78 \%)$ and female were $4(22 \%)$ with a male female ratio of 3.5:1. Mean age was $4.65 \pm 3.23$ year and mean wasp bites number was 30.80 15.46 (range11-48). Four patients (22\%) developed secondary hypertension. kidney biopsy showed acute tubulointerstitial nephritis in13 (72\%) and Acute tubular necrosis in 5(18\%) children. All patients recovered after peritoneal dialysis but recovery of renal function was delayed in victims with larger numbers of wasp envenomation, and they needed multiple peritoneal dialyses and had other severe complications.

Conclusions: Clinicians should be aware that children with multiple wasp stings are at risk of AKI and secondary hypertension. We suggest hospitalization as early as possible to provide intensive dialytic support to ensure good renal recovery with shortest period and reduce morbidity.

Keywords: Acute Kidney Injury; Children; Wasp stings 


\section{Advances in Clinical Toxicology}

Abbreviations: ATN: Acute Tubular Necrosis; CBC: Complete Blood Count; CPK: Creatine chosphokinase; LDH: Serum Lactate Dehydrogenase; LFT: Liver Function Test; ARF: Acute Renal Failure; AKI: Acute Kidney Injury; BICH: Bangladesh Institute of Child Health.

\section{Introduction}

Wasp is a member of the vespid subgroup in the order Hymenoptera that typically sting following provocation. This usually occurs in the late summer and in early fall, when large numbers of hungry wasp are attracted to the food of humans eating outdoors [1]. Wasp venom is a complex substance consisting of proteins which can affect various tissues [2]. Usually wasp stings are associated with only local reactions. But these are frightening, when masses of wasps attack, not only because of the severe pain but also because of the possibility of fatality [3]. Multiple wasp stings may result in anaphylaxis, hemolysis, rhabdomyolysis, thrombocytopenia, elevated hepatic serum enzymes, acute renal failure (ARF) and multiple organ dysfunction [4]. Acute kidney injury due to wasp stings is an uncommon but serious complication. Renal damage may be caused by direct toxin or nephrotoxicity, hypotension leading to ischemic tubular necrosis and nephropathy due to hemoglobinemia and myoglobinemia. Renal biopsy usually reveals acute tubular necrosis and acute interstitial nephritis [5]. More than half of the victims of multiple wasp stings develop AKI, and most of these patients require peritoneal dialysis or intermittent hemodialysis [6]. The mortality rate has been reported to be as high as $25 \%$ among the patient who experience AKI due to wasp stings and probably death is due to a direct toxic effect of the venom $[7,8]$. Several studies show that the injected venom intensity and the prognosis are directly associated with the number of bee stings $[9,10]$. Another point to consider is that, the sting continue to inject venom after be detached from the insect body, so the amount of venom inoculation also depend on timing of removal of bee stings from the victim's body is important issue but the method of removal does not seem to affect the quantity of venom received [11]. Zhang, et al. found that the incidence of AKI after multiple wasp stings was as high as $84.5 \%$ and $80 \%$ of the AKI patients were able to achieve complete kidney recovery; however, $9.3 \%$ of them died, and $10.7 \%$ of them developed CKD [12].

In this study, we analyzed children havingAKI due to multiple wasp stings in a tertiary care pediatric hospital in Bangladesh during a 2-year period who were treated with peritoneal dialysis along with other standard supportive care, to find out the type of renal injury and to observe the immediate outcomes.

\section{Materials and Methods}

It was a prospective study conducted in Dhaka Shishu (Children) Hospital from July 2012 to June 2014. During this period, all admitted children with AKI following wasp bite were included in the study. The diagnosis of wasp stings was based on clinical history and the findings on physical examination. The diagnosis of AKI was determined according to the 2012 Kidney Disease: Improving Global Outcomes guidelines [13]. Demographic details including age, sex, clinical history and clinical findings including number of wasp bites, duration from bite to reach the hospital, secondary hypertension and other complications were collected. Lab investigations including complete blood count (CBC), renal function tests, coagulation profile, creatinechosphokinase (CPK), serum lactate dehydrogenase (LDH) and liver function test (LFT) along with renal biopsy were performed in each patient.All patients received standard supportive care and underwent peritoneal dialysis. Number of Dialysis, days of Improvement of oliguria and hospital stay were noted andall data entered in a pre-formed data sheet and for statistical analysis, data were expressed as mean ( \pm standard deviation), percentage and range wherever appropriate, by SPSS version 12 .

\section{Results and Discussion}

A total 18 children having AKI following wasp bite were included in the study. Among them $14(78 \%)$ was male and female were $4(22 \%)$ with a male female ratio of 3.5:1 Figure 1. Mean age was $4.65 \pm 3.23$ year. All children had multiple sting marks varying in number from 11 to 48 (mean30.80 \pm 15.46 ). Characteristics of wasp bite patients are described in Table 1. Most of sting marks were seen predominantly on the face, trunk and upper extremities.

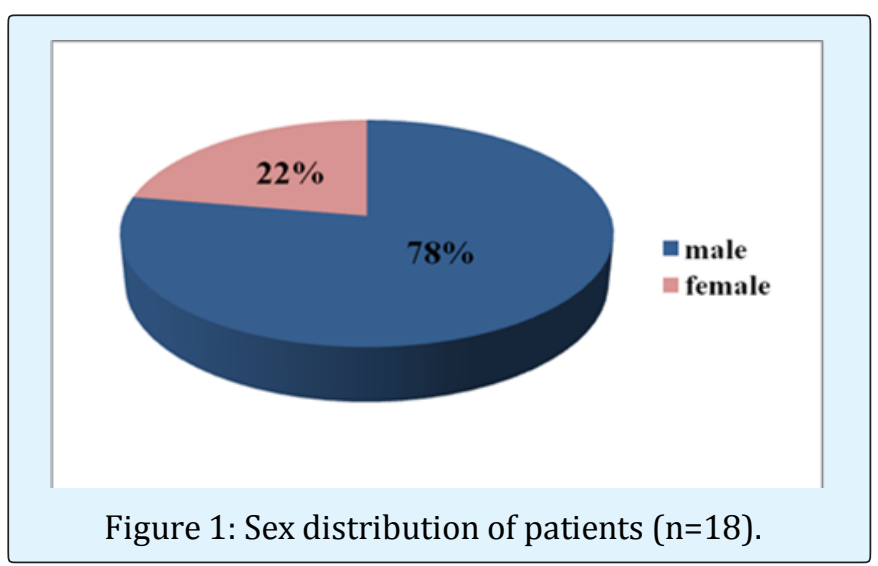




\begin{tabular}{|c|c|c|}
\hline & Mean \pm SD & Range \\
\hline Age of the patient (year) & $4.65 \pm 3.23$ & $3.25-10$ \\
\hline Number of wasp bites & $30.80 \pm 15.46$ & $11-48$ \\
\hline $\begin{array}{c}\text { Duration from bite to reach } \\
\text { hospital (days) }\end{array}$ & $3.8 \pm 2.58$ & $1-8$ \\
\hline Hospital stay (days) & $17 \pm 8.71$ & $7-30$ \\
\hline
\end{tabular}

Table 1: Characteristics of wasp bite patients.

The main clinical features at presentation were oliguria in all children $(100 \%)$, hematuria in $8(44 \%)$, hypertension in $4(22 \%)$, jaundice in $8(44 \%)$, lethargy in $9(50 \%)$ and pallor and oedema in $100 \%$ children, but no cardiac or neurological manifestations were seen in any patient. Evidence of allergic reaction was present in 7 children whereas one patient had history suggestive of anaphylaxis.All patients had elevated serum CPK, different degrees of Anemia. Altered liver function tests were seen in $7(39 \%)$, mild thrombocytopenia in $4(22 \%)$ andalteredcoagulation parametersin 6(33\%) children.These finding are consistent with the studies reported by Sigdelet al and Vikrant, et al. [14,15].

Inour series, kidney biopsy showed acute tubulointerstitial nephritis in $13(72 \%)$ and Acute tubular necrosis in 5(18\%) children.But according to the study conducted by Thiruventhirannet al, Acute tubular necrosis (ATN) was the most common biopsy histological finding in cases of acute renal failure caused by wasp stings [7]. Similar finding was found by Sakhuja, et al. they reported that 3 of their 5 histopathological report of AKI patients due to wasp sting had evidence of acute tubular necrosis [16]. But Sharma et al and Chao et al both found acute tubule interstitial nephritis in their cases. For the $1^{\text {st }}$ time Zhang et al reported that acute tubulointerstitial nephritis could lead to AKI following massive wasp stings [17-19].

In our study all patients recovered after peritoneal dialysis and improvement of oliguria occurred over a mean duration of $4.2 \pm 1.7$ days (range 2-20 days). The time lag between sting and hospitalization ranged from 1 to 8 (mean 3.8 \pm 2.58 ) days and the mean length of hospital stay was 17 \pm 8.71 (range 7-30) days (table I). Our observation was, recovery of renal function was delayed in victims with delayed reaching the hospital and having larger numbers of wasp envenomation and they needed multiple peritoneal dialyses and had other severe complications Tables $1 \& 2$. This findings are consistent with the study reported by Xie, et al. they showed that elevation of all laboratory parameters was higher in patients with $>10$ stings than in patients with $\leq 10$ stings [20].

\begin{tabular}{|c|c|c|c|}
\hline & $<\mathbf{1 5 ,} \mathbf{n = 3}$ & $\begin{array}{c}\mathbf{1 5 - 3 5 ,} \\
\mathbf{n = 8}\end{array}$ & $\mathbf{> 3 5 , \mathbf { n } = \mathbf { 7 }}$ \\
\hline $\begin{array}{c}\text { Secondary } \\
\text { Hypertension }\end{array}$ & 0 & 0 & 4 \\
\hline Hemolysis & 2 & 5 & 7 \\
\hline Septicemia & 1 & 2 & 3 \\
\hline Liver injury & 0 & 1 & 2 \\
\hline No. of dialysis done & 1 & 2 & $>2$ \\
\hline $\begin{array}{c}\text { Improvement of } \\
\text { oliguria (days) }\end{array}$ & $2-5$ & $4-10$ & $5-20$ \\
\hline Days of hospital stay & $7-10$ & $12-16$ & $20-30$ \\
\hline
\end{tabular}

Table 2: Relation of clinical co-morbidities with the number of wasp bite

\begin{tabular}{|c|c|c|c|}
\hline & $\begin{array}{c}<\mathbf{3} \text { days, } \\
\mathbf{n = 2}\end{array}$ & $\begin{array}{c}\mathbf{3 - 7} \text { days, } \\
\mathbf{n = 6}\end{array}$ & $\begin{array}{c}\mathbf{7} \text { days, } \\
\mathbf{n = 1 1}\end{array}$ \\
\hline $\begin{array}{c}\text { Secondary } \\
\text { Hypertension }\end{array}$ & 0 & 0 & 4 \\
\hline Hemolysis & 1 & 5 & 8 \\
\hline Septicemia & 0 & 3 & 7 \\
\hline Liver injury & 1 & 2 & 3 \\
\hline $\begin{array}{c}\text { Improvement of } \\
\text { oliguria (days) }\end{array}$ & $2-3$ & $5-10$ & $5-20$ \\
\hline No. of dialysis done & 1 & 2 & $>2$ \\
\hline Days of hospital stay & $7-10$ & $12-16$ & $20-30$ \\
\hline
\end{tabular}

Table 3: Relation of duration from bite to reach hospital and consequence of presentation

\section{Conclusion}

Clinicians should be aware that children with multiple wasp stings are at risk of AKI and multi organ involvement. Our observation was, patients having less envenomation and early hospitalization had less severe complications and shorter hospital stay. We suggest hospitalization as early as possible to provide intensive dialytic support to ensure good renal recovery and reduce morbidity.

\section{Acknowledgements}

Authors are very thankful to Nephrology team and post-graduate students of the Department of Pediatric Nephrology, Dhaka Shishu (Children) Hospital, Bangladesh, for the assistance provided to the patients. There is no source of funding for the study for each author and for the manuscript preparation. 


\section{Conflict of Interest}

The author declares no financial interest or any conflict of interest.

\section{References}

1. Edwards R (1980) Social Wasps their Biology and Control. East Grinstead, Rentokil Ltd.

2. Singh LR, Singh YT, Singh S, Singh NSK, Sharma LR (2005) Acute renal failure in a child following multiple wasp stings. Indian J Nephrol 15: 95-97.

3. Hommel D, Hulin A, Bollandard F (1998) Multiple African honeybee stings and acute renal failure. Nephron 78(2): 235-236.

4. Chaiyapak T, Pattaragarn A, Supavekin S, Visitsunthorn N, Sumboonnanonda A (2012) Wasp stings with multiple organ dysfunction in children. Siriraj Med J 64: 80-83.

5. Watana D, Anuwuthinawin D, Khoprasert S, Limpokiyagul PVS (1989) Multiple wasp stings in children a review. Chula Med J 33(9): 659-64.

6. Bresolin NL, Carvalho LC, Goes EC, Fernandes R, Barotto AM (2002) Acute renal failure following massive attack by Africanized bee stings. Pediatr Nephrol 17(8): 625-627.

7. Thiruventhiran T, Goh BL, Leong CL, Cheah PL, LooiLM, et al. (1999) Acute renal failure following multiple wasp stings. Nephrol Dial Transplant 14: 214-217.

8. Nace L, Bauer P, Lelarge P, Bollaert PE, Larcan A, et al. (1992) Multiple European wasp stings and acute renal failure. Nephron 61(4): 477.

9. Franca FOS, Benvenuti LA, Fan HW, Dos Santos DR, Hain SH, et al. (1994) Severe and fatal mass attacks by "killer" bees (Africanized honey bees Apis mellifera scutellata) in Brazil clinicopathological studies with measurement of serum venom concentrations. Q J Med 87(5): 269-282.

\section{Advances in Clinical Toxicology}

10. Mejia G, Arbelaez M, Henao JE, Sus AA, Arango JL (1986) Acute renal failure due to multiple stings by Africanized bees. Ann intern Med 104(2): 210-211.

11. Visscher PK, Vetter RS, Camazine S (1996) Removing bee stings. Lancet 348(9023): 301-302.

12. Zhang L, Yang Y, Tang Y, Zhao Y, Cao Y, et al. (2013) Recovery from AKI following multiple wasp stings A case series. Clin J Am Soc Nephrol 8(11): 1850-1856.

13. Kidney Disease: Improving Global Outcomes (KDIGO) Acute Kidney Injury Work Group (2012) KDIGO clinical practice guideline for acute kidney injury. Kidney Int 2(Suppl) 1-13.

14. Sigdel MR, Raut K (2013) Wasp bite in a referral hospital in Nepal. J Nepal Health Res Counc 11(25): 244-250.

15. Vikrant S, Pandey D, Machhan P, Gupta D, Kaushal SS, et al. (2005) Wasp envenomation-induced acute renal failure a report of three cases. Nephrology (Carlton)10(6): 548-552.

16. Sakhuja V, Bhalla A, Pereira BJ, Kapoor MM, Bhusnurmath SR, et al. (1988) Acute Renal Failure following multiple hornet stings. Nephron 49(4): 319321.

17. Sharma A, Wanchu A, Mahesha V, Sakhuja V, Pradeep $B$, et al. (2006) Acute tubule-interstitial nephritis leading to acute renal failure following multiple hornet stings. BMC Nephrol 7: 18.

18. Chao YW, Yang AH, Ng YY, Yang WC (2004) Acute interstitial nephritis and pigmented tubulopathy in a patient after Wasp stings. Am J Kidney Dis 43(2): e1519.

19. Zhang R, Meleg-Smith S, Batuman V (2001) Acute tubulointerstitial nephritis. Am J Dis 38: e33.

20. Xie C, Xu S, Ding F, Xie M, Lv J, et al. (2013) Clinical features of severe wasp sting patients with dominantly toxic reaction analysis of 1091 cases. PLoS One 2013 8(12): e83164. 